\title{
The Method of Determining Stress Levels Regarding the Electrical ALT through Optical Temperature Sensor
}

\author{
Haeng-Soo Ryu ${ }^{\dagger}$, Gyu-Hwan Han*, and Nam-Sik Yoon**
}

\begin{abstract}
Electrical endurance is the critical characteristic of Magnetic contactors (MCs), which are widely used in such power equipment as elevators, cranes, and factory control rooms in order to close and open control circuits. Testing time, however, is not short in typical cases in which some method of reducing the testing period is required. This study shows the method of determining the stress level of electrical ALT (Accelerated Life Test) through optical temperature sensor and the relationship between $0.05 \mathrm{~s}$ and $0.1 \mathrm{~s}$ for on-time. The tool used for analyzing the test result is MINITAB. I will propose the method of determining the optimized stress level through optical temperature sensor, which will contribute to minimize the testing time and development period and also raise the product reliability.
\end{abstract}

Keywords: Accelerated Life Test, Magnetic Contactor, MINITAB, Optical Temperature Sensor

\section{Introduction}

The magnetic contactor is composed of the magnetic and the contactor point parts and the frames required to put them together, which are shown in Fig. 1. It is closing the contact point by exciting the magnetic coil that opens the contact point by degaussing the magnetic coil, thereby switching the load. The capacity range of the magnetic switch for alternating the current is from $110 \mathrm{~V}$ to $690 \mathrm{~V}$ and from $5 \mathrm{~A}$ to $800 \mathrm{~A}$. The magnetic switch is generally used below $800 \mathrm{~A}$.

Regarding the accelerated life test, various studies have been researched taking into account the stress caused by temperature and voltage $[6,9,10]$. Also, electrical stress and the parameter of the degradation were considered [5, 11]. The former study involving electrical stress is focused on the test current but this study depicts the stress as the number of operating cycles. Moreover, the stress levels are determined by using an optical temperature sensor.

The Weibull distribution is commonly used for product life, because it models either increasing or decreasing failure rates simply. It is also used as the distribution for product properties such as strength (electrical or mechanical), elongation, resistance, etc., in accelerated life testing. It is used to describe the life or roller bearing, electronic components, ceramics, capacitors, and dielectrics in accelerated life testing. According to extreme value theory, it may describe a "weak link" product. Such a

$\dagger$ Corresponding Author: LS Industrial Systems, Co, Ltd, Korea (hsryu@1sis.biz)

* LS Industrial Systems, Co, Ltd, Korea (hsryu@1sis.biz)

** Dept. of Electrical and Electronic Engineering, Chungbuk National University, Korea

Received 13 November 2007; Accepted 10 March, 2008 product consists of many parts from the same life distribution, and the entire product fails with the first part failure that takes place. The Weibull cumulative distribution is given by Eq. (1)

$$
F(t)=1-\exp \left[-\left(\frac{t}{\eta}\right)^{\beta}\right], t>0
$$

The shape parameter $\beta$ and the scale parameter $\eta$ are positive. $\eta$ is also called the characteristic life. It is always the $63.2 \mathrm{nd}$ percentile. $\eta$ has the same units as $\mathrm{t}$, for example, hours, months, cycles, etc. $\beta$ is a unitless pure number; it is also called the $\beta$ parameter and "slope" parameter when estimated from the Weibull plot. For most products and materials, $\beta$ is in the range 0.5 to 5. The Weibull probability density is given by Eq. (2)

$$
f(t)=\left(\frac{\beta}{\eta^{\beta}}\right) t^{\beta-1} \exp \left[-\left(\frac{t}{\eta}\right)^{\beta}\right], t>0
$$

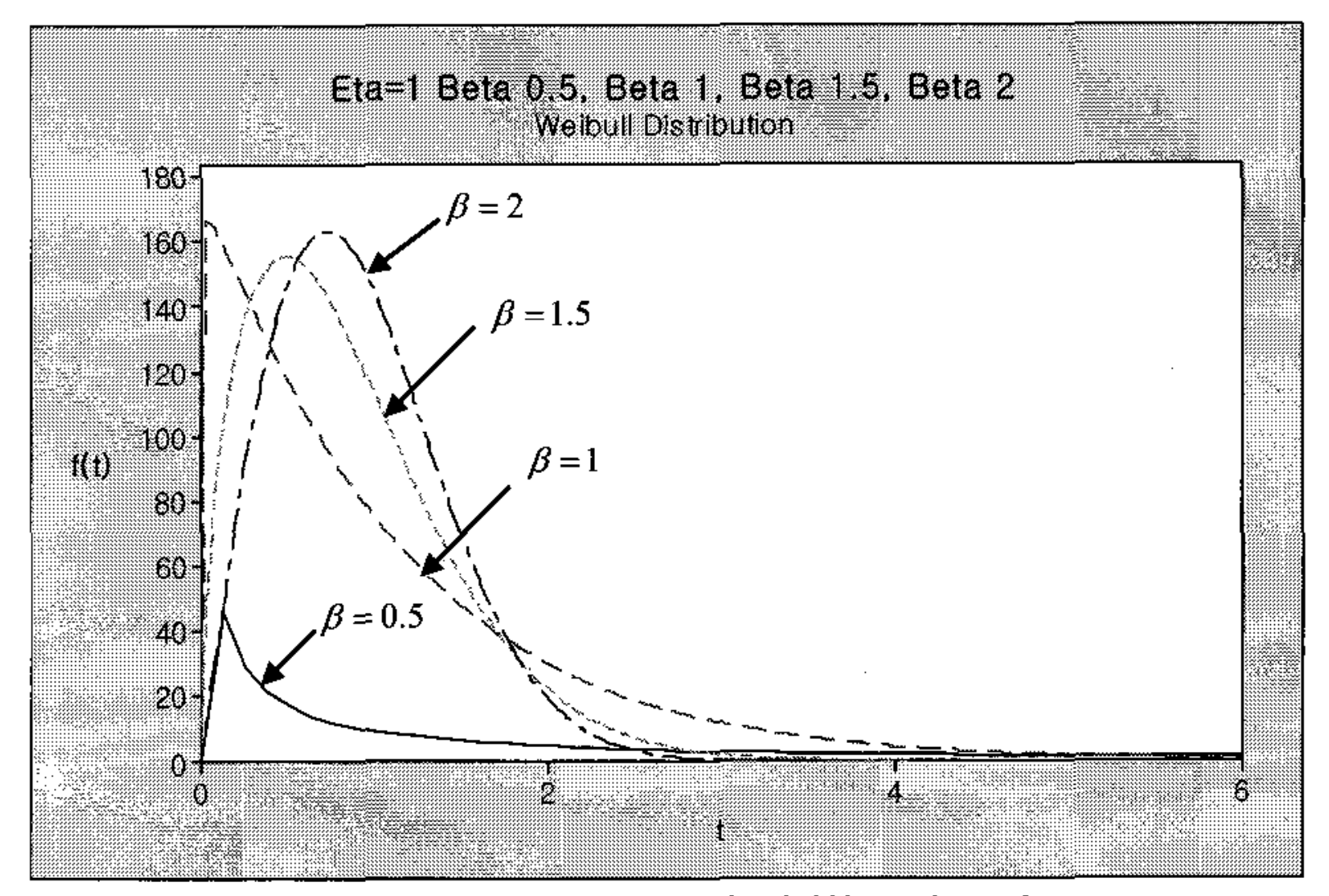

Fig. 1. Weibull Probability density 
The Weibull probability density shows that $\beta$ determines the shape of the distribution, and $\eta$ determines the spread. $\beta$ determines the spread in log life; high (low) $\beta$ corresponds to small (great) spread. For $\beta=1$, the Weibull is the exponential distribution, see Fig. 2. For much life data, the Weibull distribution fits better than the exponential, normal, and lognormal distributions. [1]

In this paper, the rating of the magnetic contactor model is $440 \mathrm{~V}-95 \mathrm{~A}$ and the coil rating is $220 \mathrm{~V}$. In order to operate the magnetic contactor, the programmable logic controller (PLC) is used. It is generally used to control the equipment through use of a ladder diagram that is programmed by the test engineer.

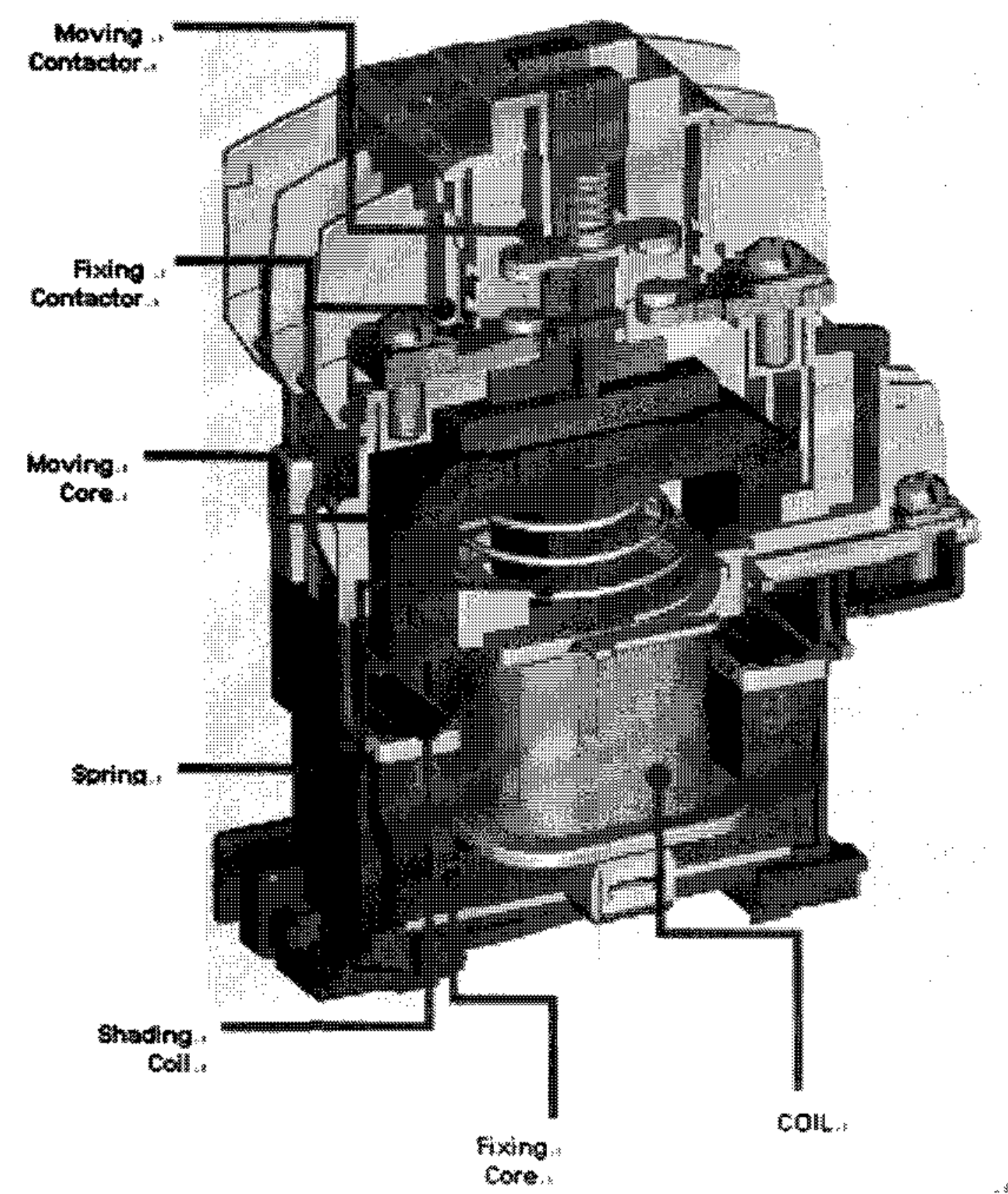

Fig. 2. The schematic diagram of the magnetic contactor

\section{ALT of Electrical endurance test}

\subsection{Selection of Life Test Conditions}

In order to choose the optimal stress levels, the optical temperature sensor was used. Fig. 3 shows the schematic of the system.

Fiber-optic thermometry is advantageous for applications in electrically hostile environments, such as where there is high electric current, or high low-frequency electric or magnetic fields, or in strong RF or micro wave fields. The dielectric nature of the optical fiber is also important in safety applications, such as in measurements in an explosive environment or when monitoring patients. Further, there is a need in many applications (e.g., engine testing or semiconductor manufacturing processes) for probes that are capable of withstanding high temperatures. The optical nature of this method also allows remote sensing, with the sensor physically separated from the rest of the system and located at a distance of even several hundreds of meters.

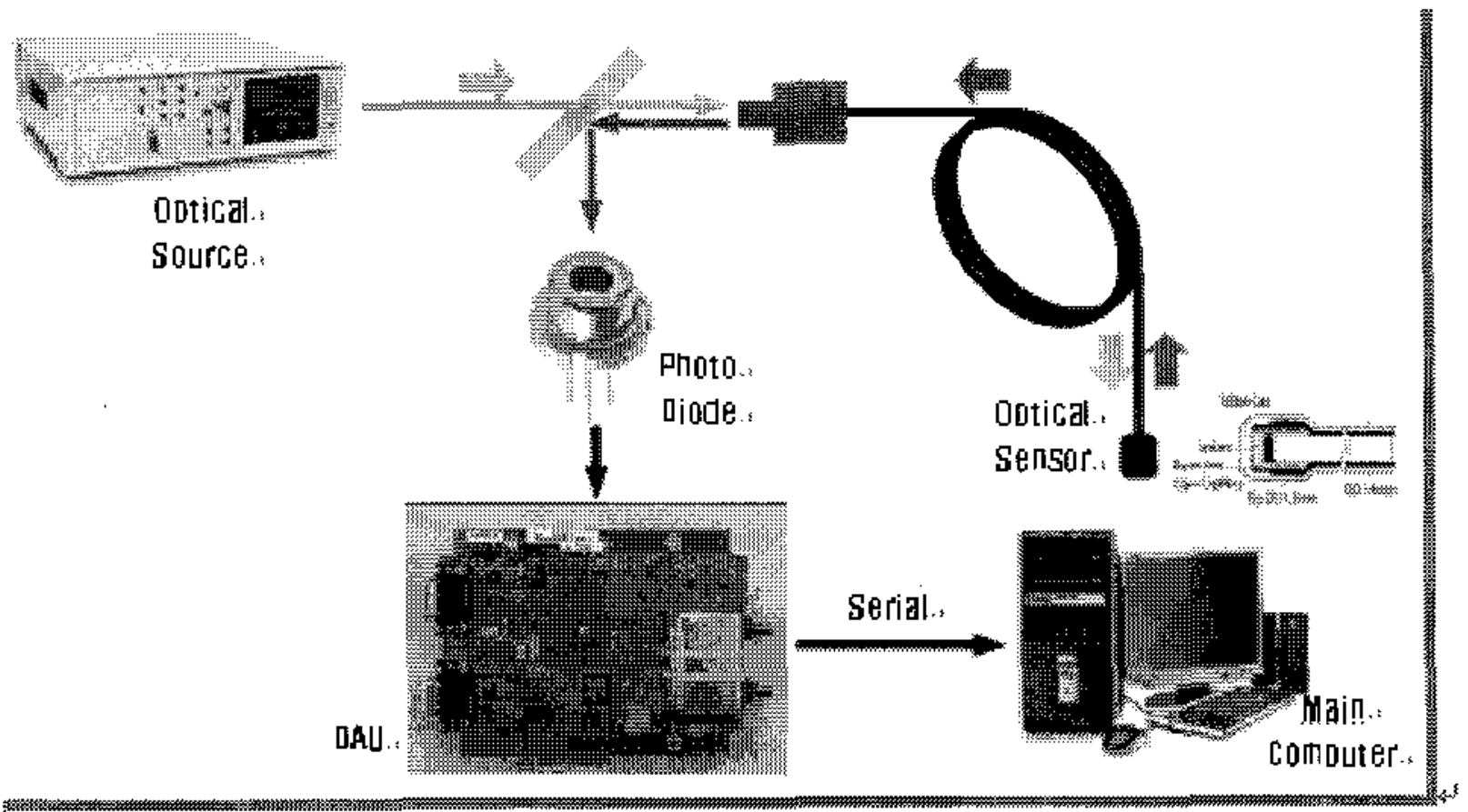

Fig. 3. System layout

The probe consists of a small sensor tip about $1 \mathrm{~mm}$ in diameter, as shown in Figure 4. The tip is adhered to one end of the fiber and encapsulated with a layer of Teflon FPA. An additional protective Teflon layer is placed over the encapsulation to ensure complete protection of the tip from mechanical and transformer oil damage. The fiber itself is also double-jacketed with Teflon PFA. The outer jacket is perforated along the length of the fiber to allow oil to penetrate into the air space between the out and the inner jacket.

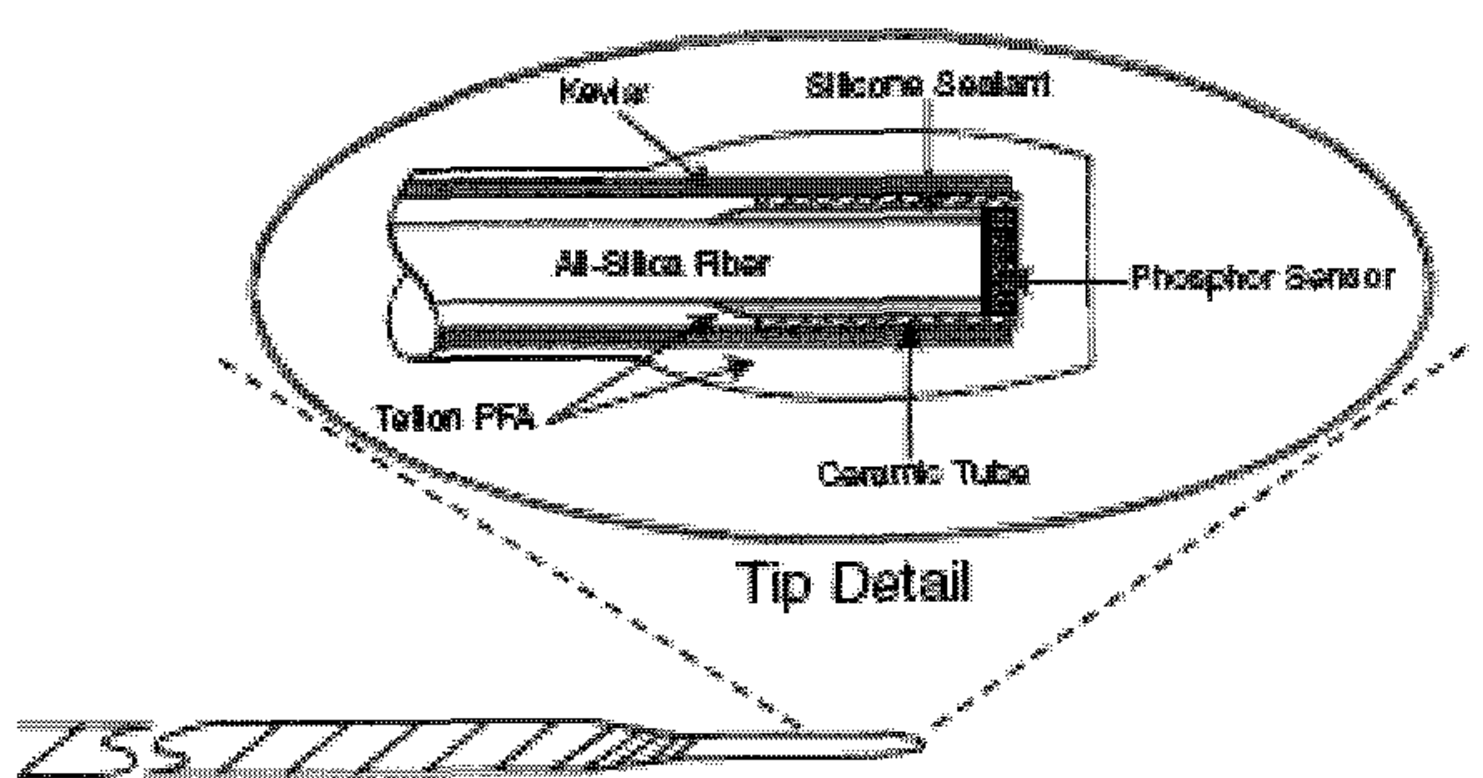

Fig. 4. Probe tip detail

The trend of the electrical terminal temperature regarding the current on/off-time is shown in Figure 5.

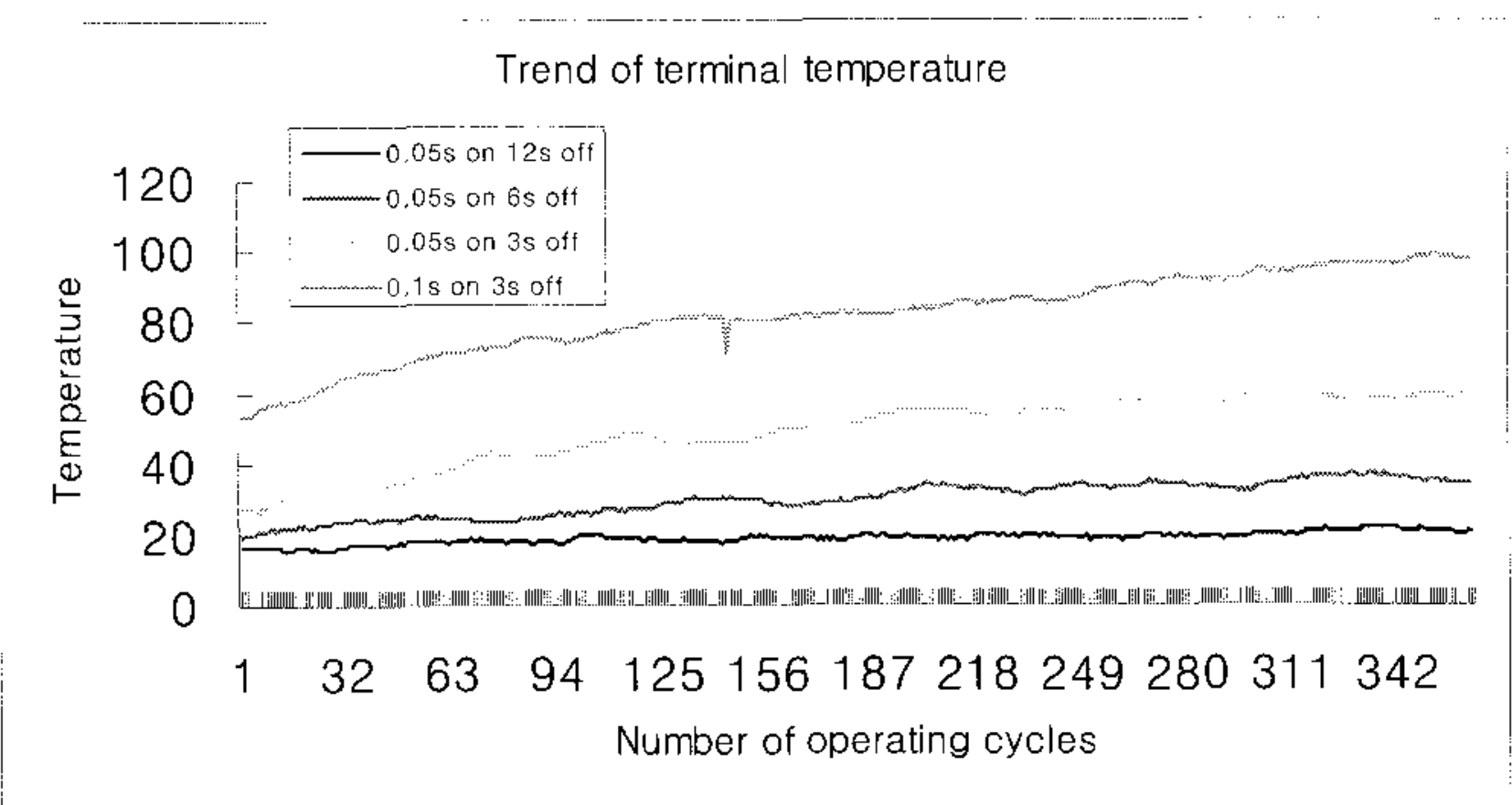

Fig. 5. Trend of terminal temperature 
The location of the optical temperature sensor is inside the magnetic contactor. This is the nearest position of the electrical arc. Fig. 6 shows the location of the optical temperature sensor.

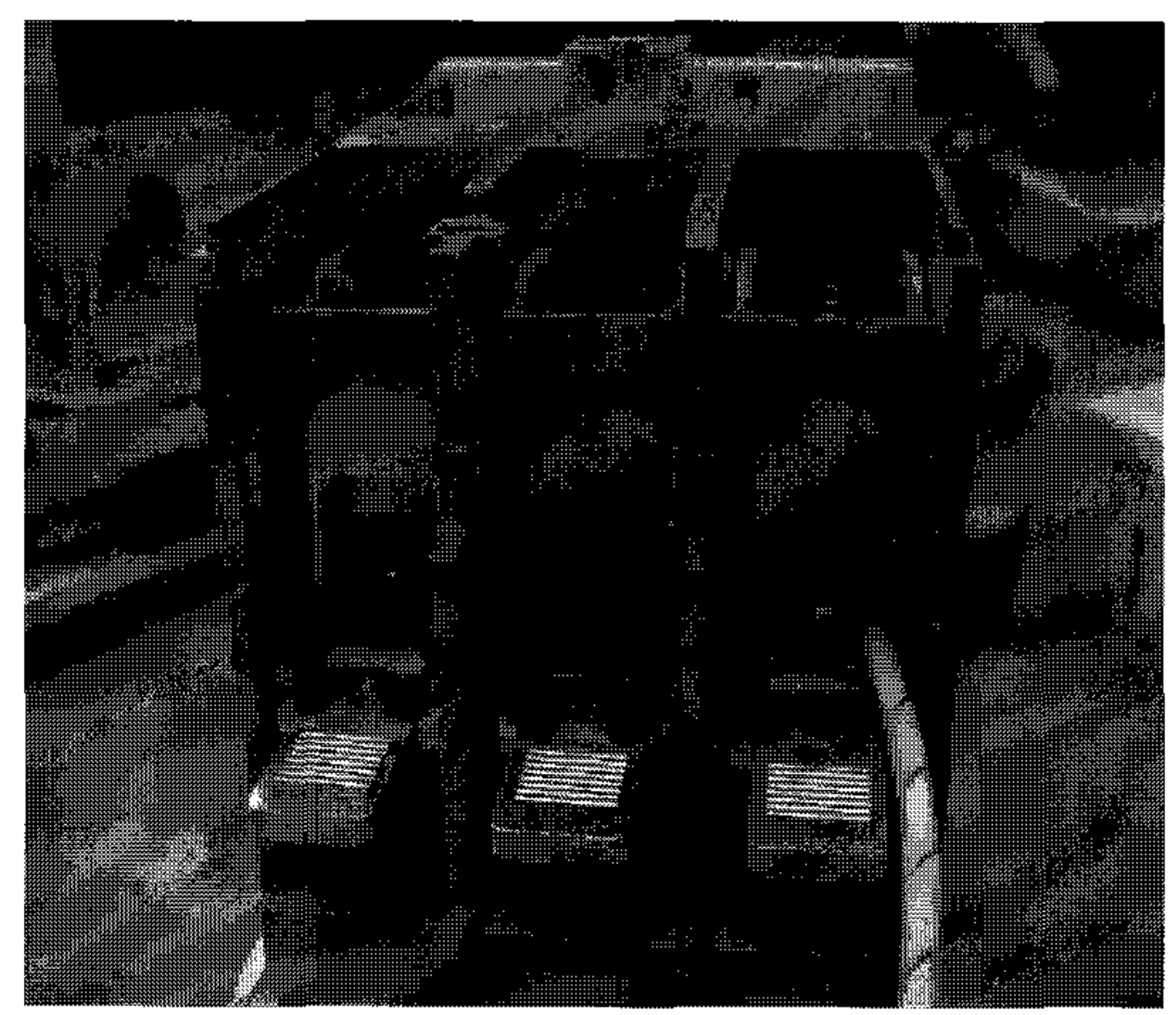

Fig. 6. The location of the optical sensor

\subsection{ALT}

There are various proposals to accelerate time consuming erosion tests by

1. reducing the number of operations at rated load and extrapolation assuming a constant erosion rate per operation;

2. increasing the switching frequency at rated electrical load assuming switching frequency does not influence the result;

3. reducing the number of operations at increased arc stress per operation (current $I_{a}$ or arcing time $t_{a}$ ) beyond the rated values and calculation of the erosion losses $\Delta m$ at rated values assuming a purely empirical similarity law of the type without proof in terms of physics $\Delta m=k \cdot I_{a}^{x} \cdot t_{a}^{y}$ $(\mathrm{k}=$ constant $)$

Extrapolation at rated stress cannot be recommended because the erosion rates must not be assumed constant over the contact life. Erosion curves might cross over and then even qualitative ranking might depend on the number of operations, and also on the device. For example, in a relay, as the contact erodes, the overtravel of the contact decreases, which lowers the opening velocity and thus can change the erosion rate of the device.

Increase of the switching frequency at rated load is the only possibility to execute life tests in acceptable time. The contact system must not be thermally over-stressed, however, in extreme cases the erosion mechanism may be changed (e.g., due to cracking and peeling off) depending on both the design of the switching device (heat dissipation from the contacts, mechanical impact) and the contact material; thus even qualitative ranking might be changed, depending on the device. Accelerated testing is limited to much lower switching frequencies than those dictated by thermal overstressing if the critical effect, e.g., fretting, frictional polymerization corrosion, and pyrolysis of organic vapors in switching arcs depends on diffusion and/or adsorption phenomena occurring between two succeeding operations.

Testing at increased electrical load may thermally overstress the contact arrangement more severely, like increased switching frequency, and correspondingly falsify the results. Additionally, deviations from the assumed similarity law have to be expected.

Similarity laws, however, are problematic at any rate since they are merely empirical and cannot be explained in terms of physics. Various authors have given values for the exponents in the wide ranges $1 \leq x \leq 3.7$ and $0.6 \leq y \leq 3$. Obviously such laws, if valid at all, are restricted to comparatively narrow ranges and dependent at least on the contact size, the thermal, mechanical (bounce), and magnetic parameters of the test device, the circuit parameters and-last but not least-on the contact material itself. Since some of these items are interrelated to current, such as contact bounce and material transfer, testing at increased loads is unlikely to be reliable for use in predicting results at lower currents. The proof of their applicability in each special case might require much more effort than the initially wanted tests.

Make and break, respectively, cause different erosion results depending on the switching duty (ohmic, capacitive, resistive, lamp, motor load, etc.). In the special case of low d.c. switching, even the direction of material transfer may be different. Since contacts in the field may be used for make only, for break only, or for various complete makeand-break cycles, there are contact erosion test machines applicable to each of those duties. Moreover, for research, separate investigations of make erosion and break erosion and even separation of make erosion at the site of contact parting (arc origin in the contact center) from that at the site of arc commutation (at the contact's edge) might yield very important information about the complex mechanisms such as material transfer and erosion rate and its dependence on various parameters of both material and design, e.g., bouncing, magnetic blast field, opening velocity, shape of contact edge, etc.

1. Make-only erosion: bouncing test machines don't duplicate erosion in commercial devices but can give repeatable erosion results. Therefore tests executed with such machines cannot replace development or acceptance tests of devices but they are needed for development and quality control of contact materials 
as well as for research. Bounce simulation models are also useful for erosion research. Test machines developed to investigate contact welding at make can also be used for make erosion tests as a rule. Some of them are suited for break erosion tests too.

2. Break-only erosion: Test machines for investigation of erosion at break only need not consider bounce problems, but have to provide a magnetic blast field when magnet blast interrupter conditions are to be simulated, because the erosion strongly depends on the time that the arc remains on the contacts. It has to be emphasized that the commutation delay causing edge erosion depends not only on the magnetic induction of the blast field but also on the opening velocity and on the geometry (height, rounding) of the contact edge at the site of commutation. For fundamental investigation it may be important not only to separate make erosion from break erosion but also to distinguish between erosion at the site of arc origin (last point of mechanical contact before parting) and erosion at the site of arc communication (at the contact's edge). The latter can be suppressed by crow barring the arc when it approaches the contact edge.

3. Make-and-break erosion: It has to be emphasized that make-and-break erosions are not necessarily equal to the sum of make erosion plus break erosion, especially not under AC 3 conditions according to IEC 60947-4-1 and when d.c. circuits are switched. Therefore test machines executing the total makeand-break cycle are required. It is convenient if such test machines are also able to measure the weld strength when opening and the contact resistance after closure.

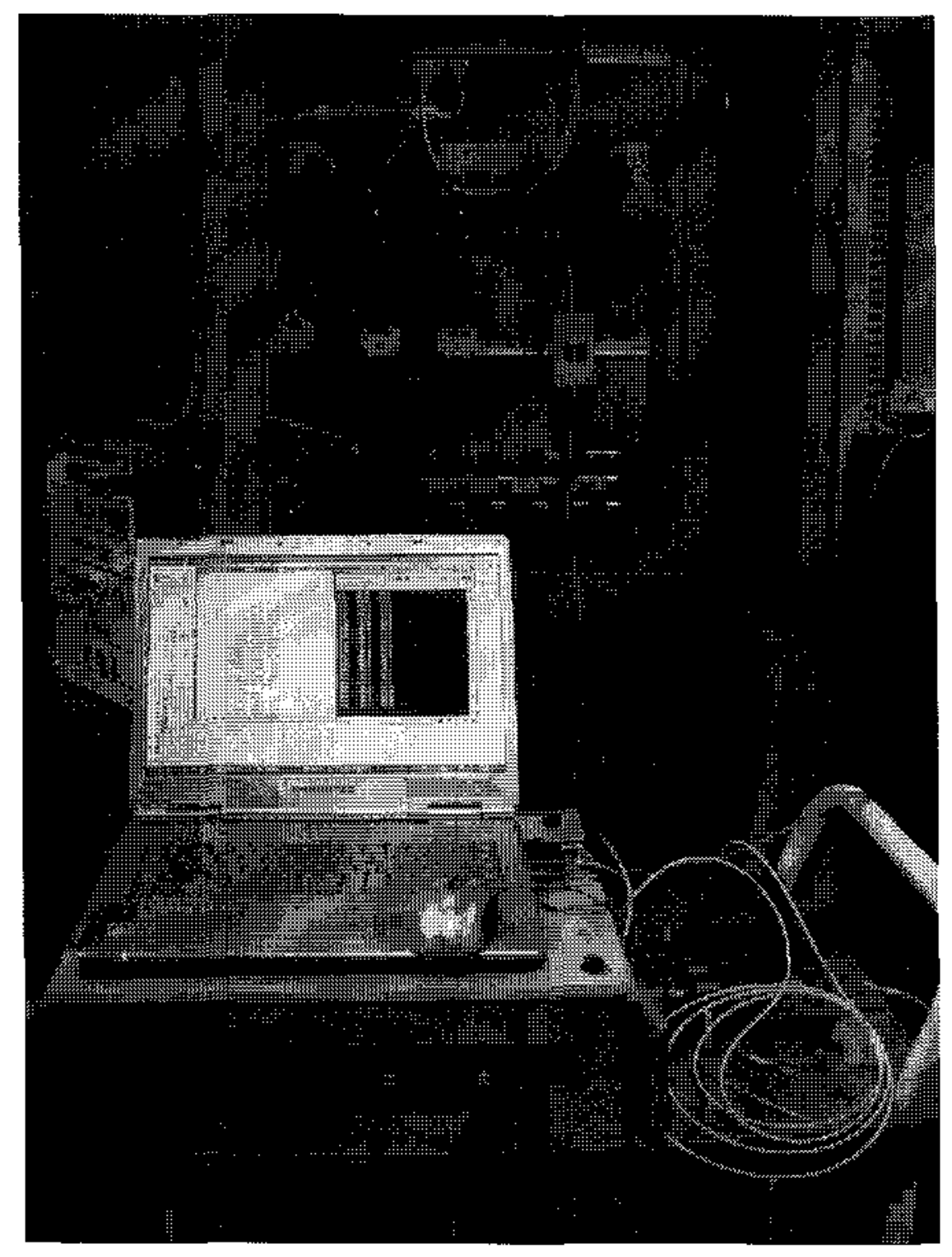

Fig. 7. The layout of the measurement device
Table 1. Accelerated life test condition

\begin{tabular}{|c|c|c|c|c|c|c|c|}
\hline Voltage & Current & PF & on-time & off-time & $\begin{array}{c}\text { Rates } \\
\text { (number of } \\
\text { operating } \\
\text { cycle/Hr) }\end{array}$ & $\begin{array}{l}\text { Measured } \\
\text { terminal } \\
\text { temperature }\end{array}$ & Remarks \\
\hline \multirow{6}{*}{$440 \mathrm{~V}$} & \multirow{6}{*}{$390 \mathrm{~A}$} & \multirow{6}{*}{0.35} & $0.05 \mathrm{~s}$ & $12 \mathrm{~s}$ & 300 & $20 \mathrm{c}$ & \multirow{6}{*}{ 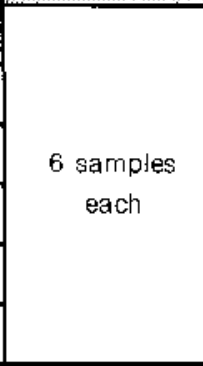 } \\
\hline & & & $0.05 \mathrm{~s}$ & $6 s$ & 600 & $38 \mathrm{C}$ & \\
\hline & & & $0.05 \mathrm{~s}$ & $3 \mathrm{~s}$ & 1200 & $80 \mathrm{c}$ & \\
\hline & & & $0.1 \mathrm{~s}$ & $12 \mathrm{~s}$ & 300 & $=$ & \\
\hline & & & $0.1 \mathrm{~s}$ & $6 \mathrm{~s}$ & 600 & - & \\
\hline & & & $0.1 \mathrm{~s}$ & $3 \mathrm{~s}$ & 1200 & 1100 & \\
\hline
\end{tabular}

As we can see the trend in Fig. 5, making and breaking rates affect the terminal temperature, causing it to be higher. According to the result, the testing condition is determined.

In order to measure the terminal temperature, the optical temperature sensor, voltage divider, current transformer, oscilloscope, and LS developed software are used. Figure 7 shows the layout of the measurement device.

\subsection{Experiment Set Up}

The test samples are fixed into the test board. Figure 8 shows the configuration of the samples. Magnetic contactors are located using the DIN-rail. A programmable logic controller (PLC) is used to check the state of the contacts.

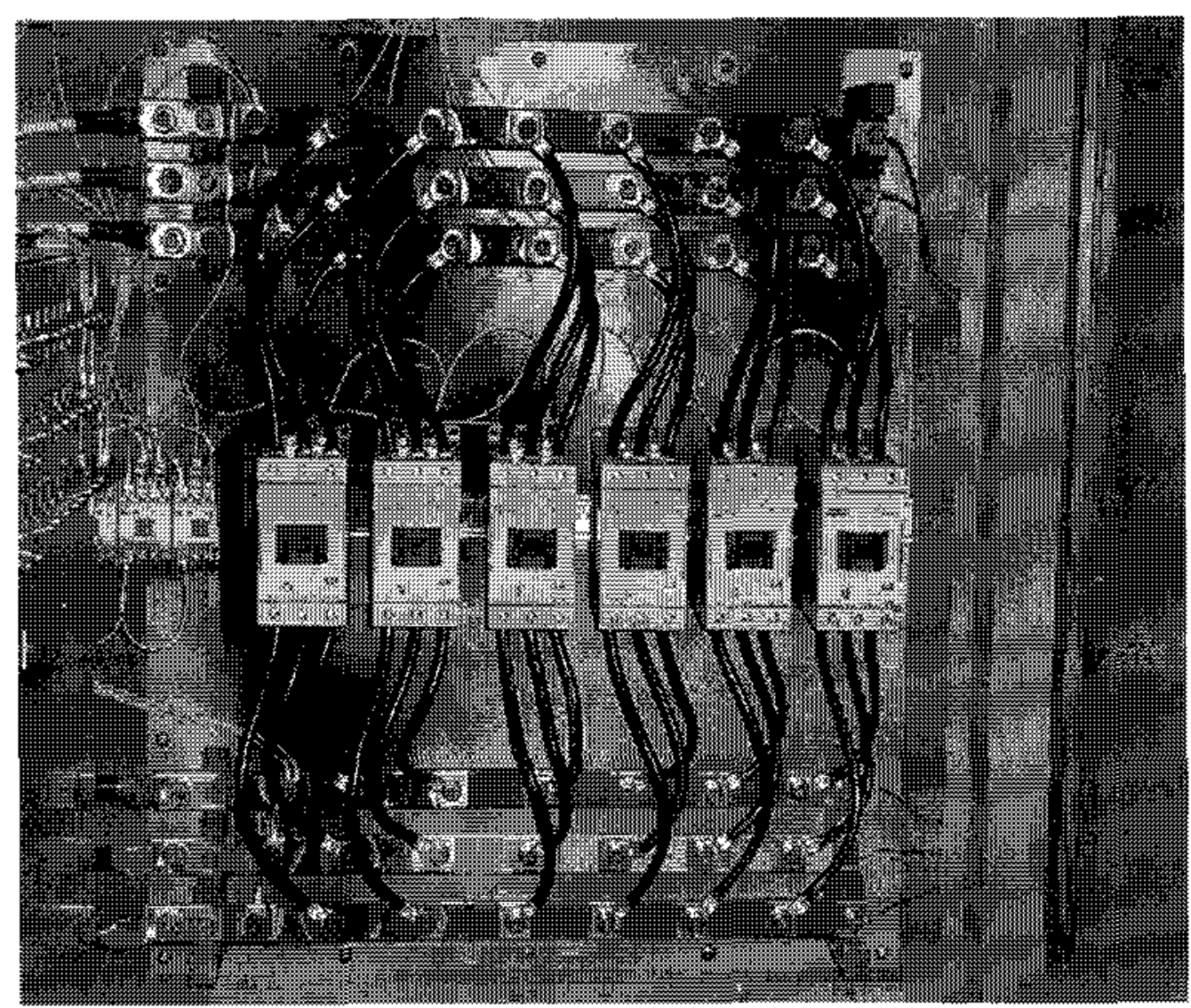

Fig. 8. The test board

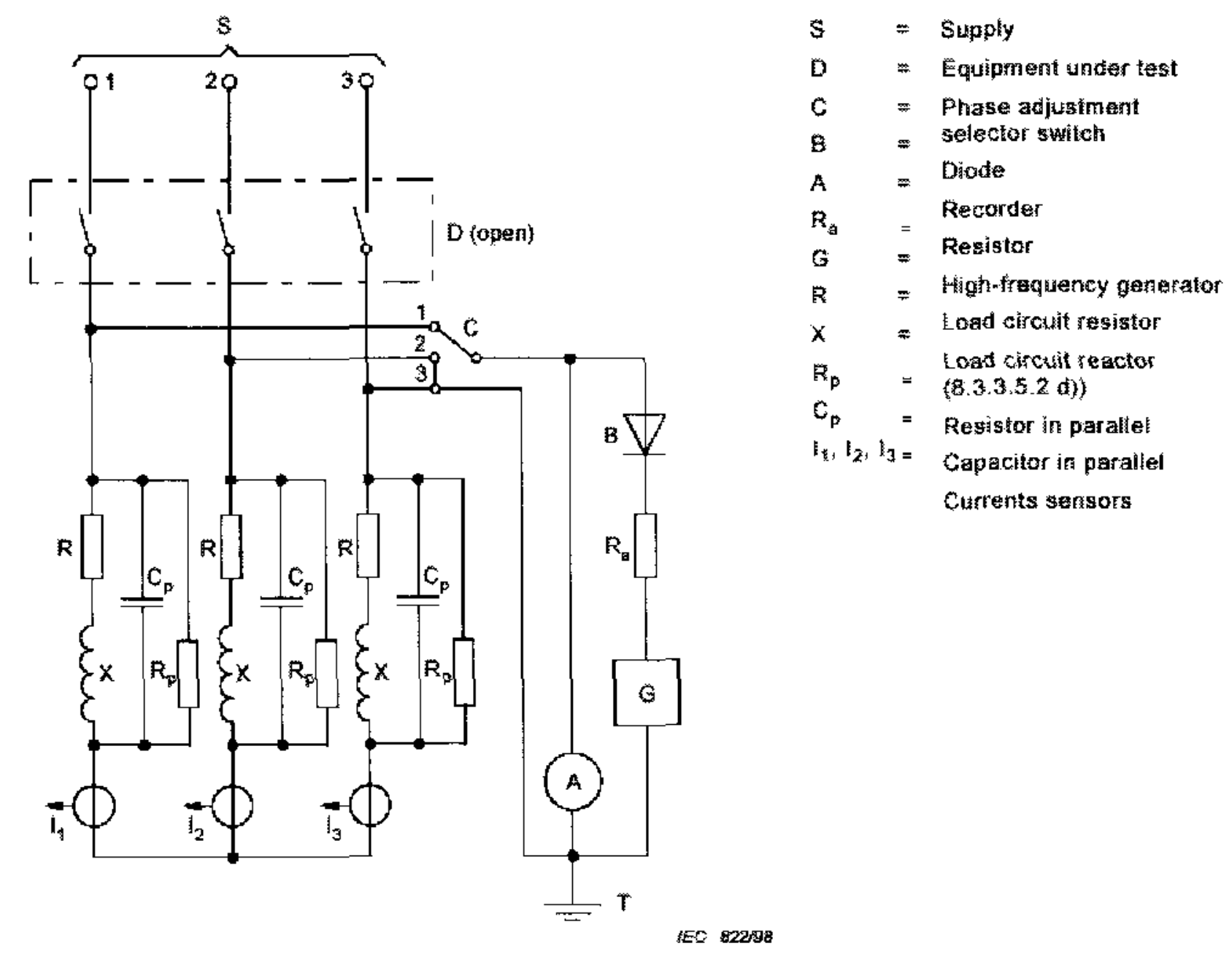

Fig. 9. The diagram of load circuit 
The diagram of the load circuit is specified in IEC 60947-1. The device on the right side (e.g., diode, recorder, etc.) of Fig. 9 is used for finding the characteristic of transient recovery voltage in the load circuit.

Also, IEC 60947-4-1 determines the test condition of electrical durability as shown in Table 2 . In this paper, the utilization category is AC 4 . The make current is 6 times $I_{e}$, the break current is 6 times $I_{e}$, and power factor $(\operatorname{Cos} \phi)$ is 0.35 because the rated operational current is greater than $17 \mathrm{~A}$. Table 1 is determined according to this standard. Moreover, the test voltage is the same as rated operational voltage. The tolerance is $\pm 5 \%$ for both voltage and current. Also, $\operatorname{Cos} \phi$ 's tolerance is \pm 0.05 .

Table 2. Verification of the number of on-load operating cycles -Conditions for making and breaking corresponding to the several utilization categories

\begin{tabular}{|c|c|c|c|c|c|c|c|}
\hline \multirow{2}{*}{ Utilization eategary } & \multirow{2}{*}{$\begin{array}{l}\text { Yalue of the rated } \\
\text { operational surrent }\end{array}$} & \multicolumn{3}{|c|}{ Make } & \multicolumn{3}{|c|}{ Break } \\
\hline & & $m_{*}$ & $u s u_{a}$ & $\cos \theta$ & $t_{\varepsilon} / t_{0}$ & $u_{\mathrm{r}} / u_{\mathrm{e}}$ & $\cos \theta$ \\
\hline$A C-1$ & All values & $t$ & 1 & 0,95 & 1 & 1 & 0,95 \\
\hline $\mathrm{AC}-2$ & All values & 2.5 & 1 & 0.65 & 2.5 & 1 & 0.65 \\
\hline \multirow[t]{2}{*}{$\mathrm{AC}-3$} & $i_{Q} \leq 17 \mathrm{~A}$ & 6 & 1 & 0,85 & 1 & 0.17 & 0,65 \\
\hline & $I_{\mathrm{g}}>-17 \mathrm{~A}$ & a & + & 0,35 & 1 & 0,17 & 0,35 \\
\hline \multirow[t]{3}{*}{$A G=4$} & $i_{8} s+78$ & 6 & 1 & 0,65 & 6 & 1 & 0,65 \\
\hline & \multirow[t]{2}{*}{$I_{\theta}>17 \mathrm{~A}$} & 6 & $t$ & 0.35 & 6 & \pm & 0.35 \\
\hline & & $m I_{8}$ & $U u_{\mathfrak{g}}$ & 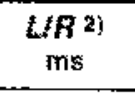 & $b_{\mathrm{s}} / f_{\mathrm{g}}$ & $b_{r} / U_{6}$ & $\begin{array}{c}\text { U/A } 2) \\
\mathrm{ms}\end{array}$ \\
\hline$D C \cdot 1$ & All values & 1 & 1 & 1 & 7 & 1 & 1 \\
\hline $\mathrm{DC}-3$ & All yaluas & $2: 5$ & + & 2 & 2.5 & 1 & 2 \\
\hline $\mathrm{DC}-5$ & All values & 2,5 & 1 & 7.5 & 2,3 & 1 & 7,5 \\
\hline \multirow{2}{*}{\multicolumn{8}{|c|}{$\begin{array}{l}t_{\mathrm{B}}=\text { raled operational current } \\
U_{\mathrm{g}}=\text { rated operational voltage }\end{array}$}} \\
\hline & voltage & & & & & & \\
\hline \multirow{2}{*}{\multicolumn{8}{|c|}{$\begin{aligned} 1= & \text { current made } \\
& \text { in a.c. the cor }\end{aligned}$}} \\
\hline & & & & & & & \\
\hline \multicolumn{8}{|l|}{$v=$ appliød voltage } \\
\hline \multicolumn{8}{|c|}{$v_{\mathrm{r}}=$ powar-trequency or d.c. recovery wo } \\
\hline \multicolumn{8}{|l|}{ k = ourrent braken } \\
\hline \multicolumn{8}{|c|}{ 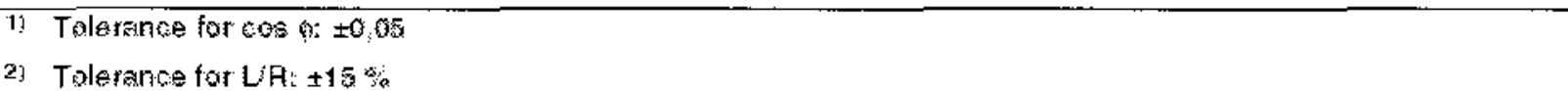 } \\
\hline
\end{tabular}

\subsection{Testing and Results}

The flow chart which shows the sequence of analyzing the reliability data in this paper is presented in Figure 10.

Figure 11 displays the finished samples. As can be seen, their contact parts are either in erosion state or fracture state.

The probability plot of the raw data is shown in Fig. 12

After verifying the experimental data, the circled data is an outlier because the failure mode is different. This is probably the initial fault sample. Figure 13 shows the probability plot when an outlier was removed.

The number of operating cycles is a critical factor for the lifetime. The shape parameter of $1200 / \mathrm{Hr}$ is approximately 1 so that it is not related with the failure mechanism of wear out. Moreover, the failure mode of $3600 / \mathrm{Hr}$ is different with other test conditions so that $1200 / \mathrm{Hr}$ and $3600 / \mathrm{Hr}$ are waived for finding the acceleration factor.

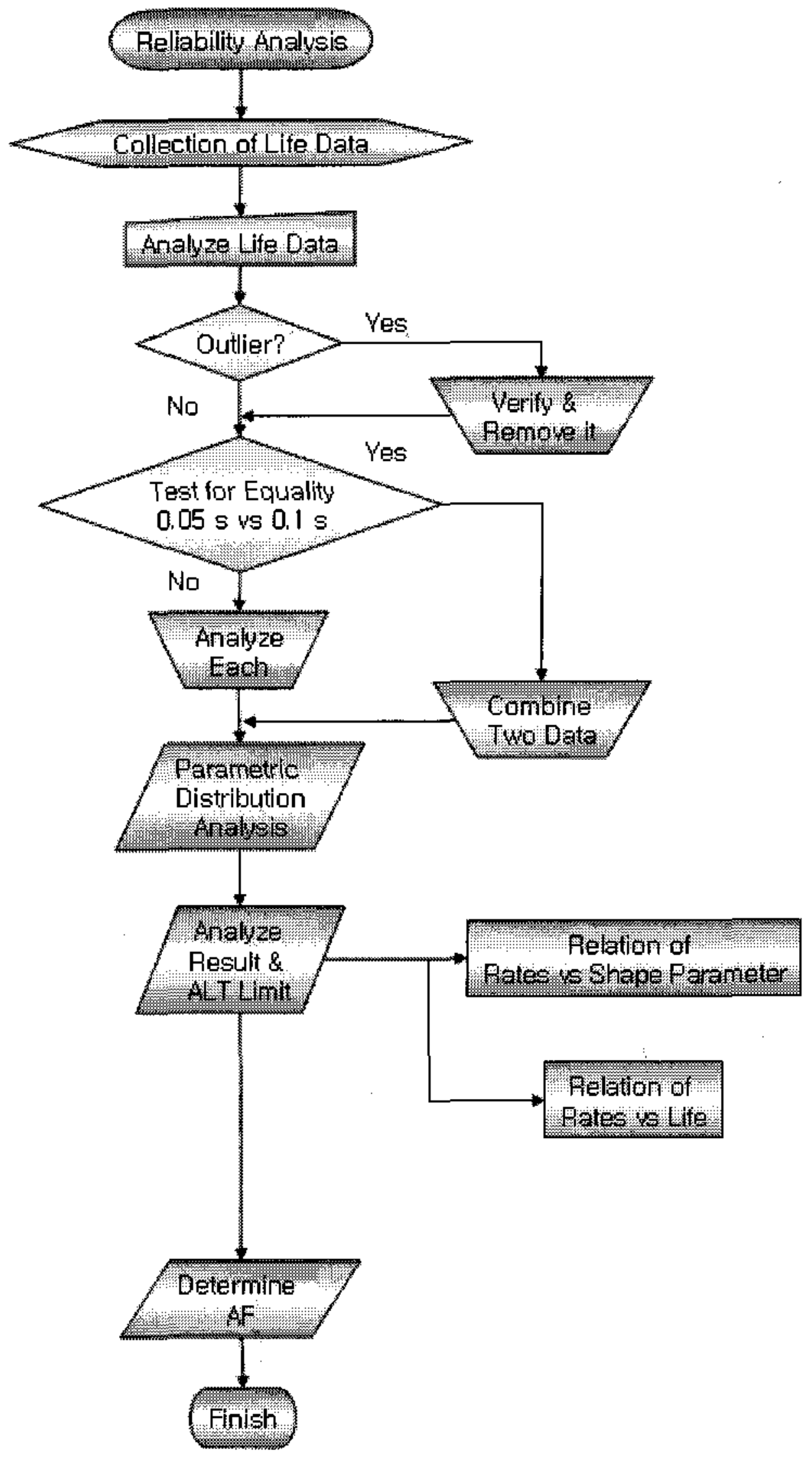

Fig. 10. Flow chart of Reliability Analysis

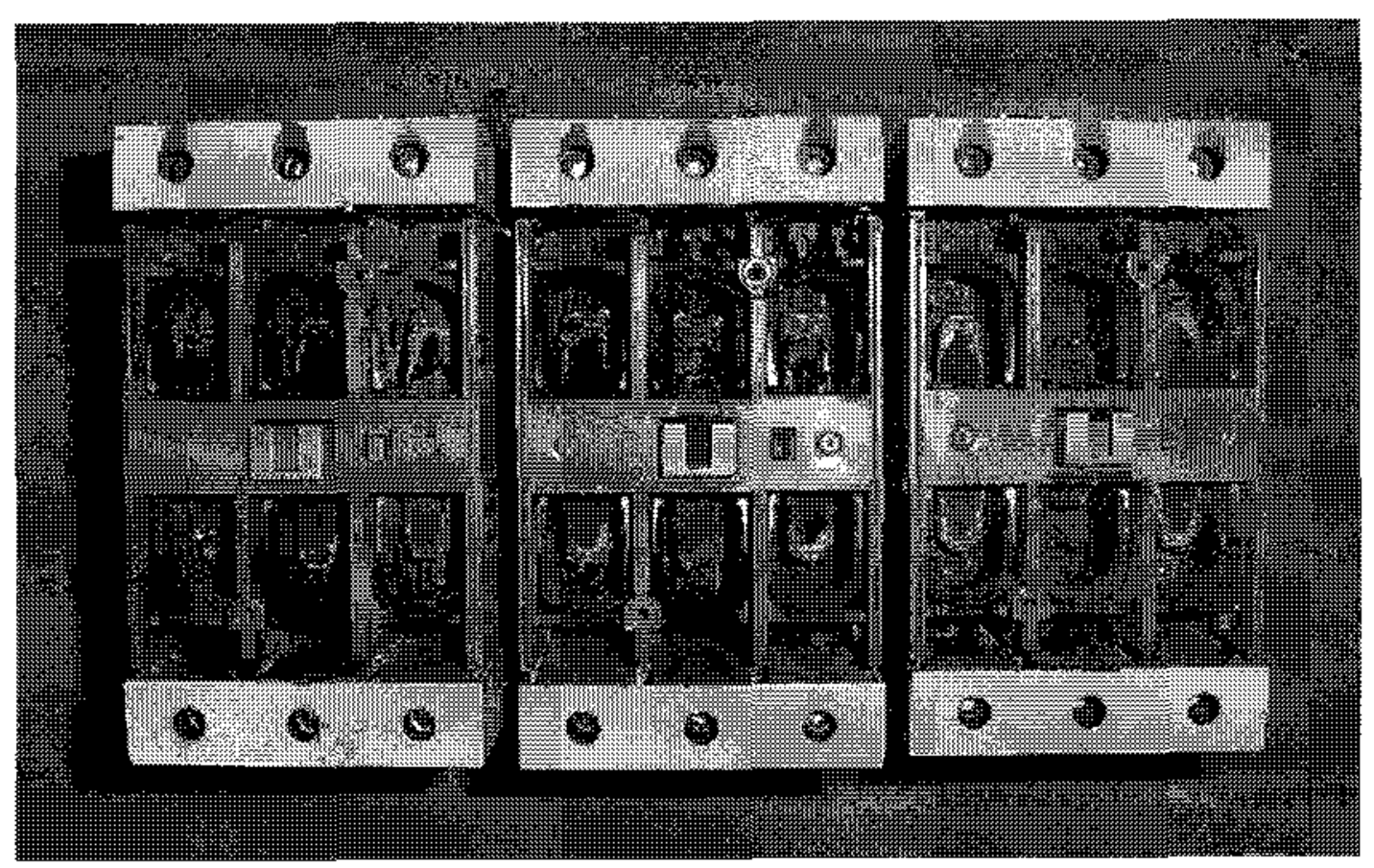

Fig. 11. The photo of finished samples

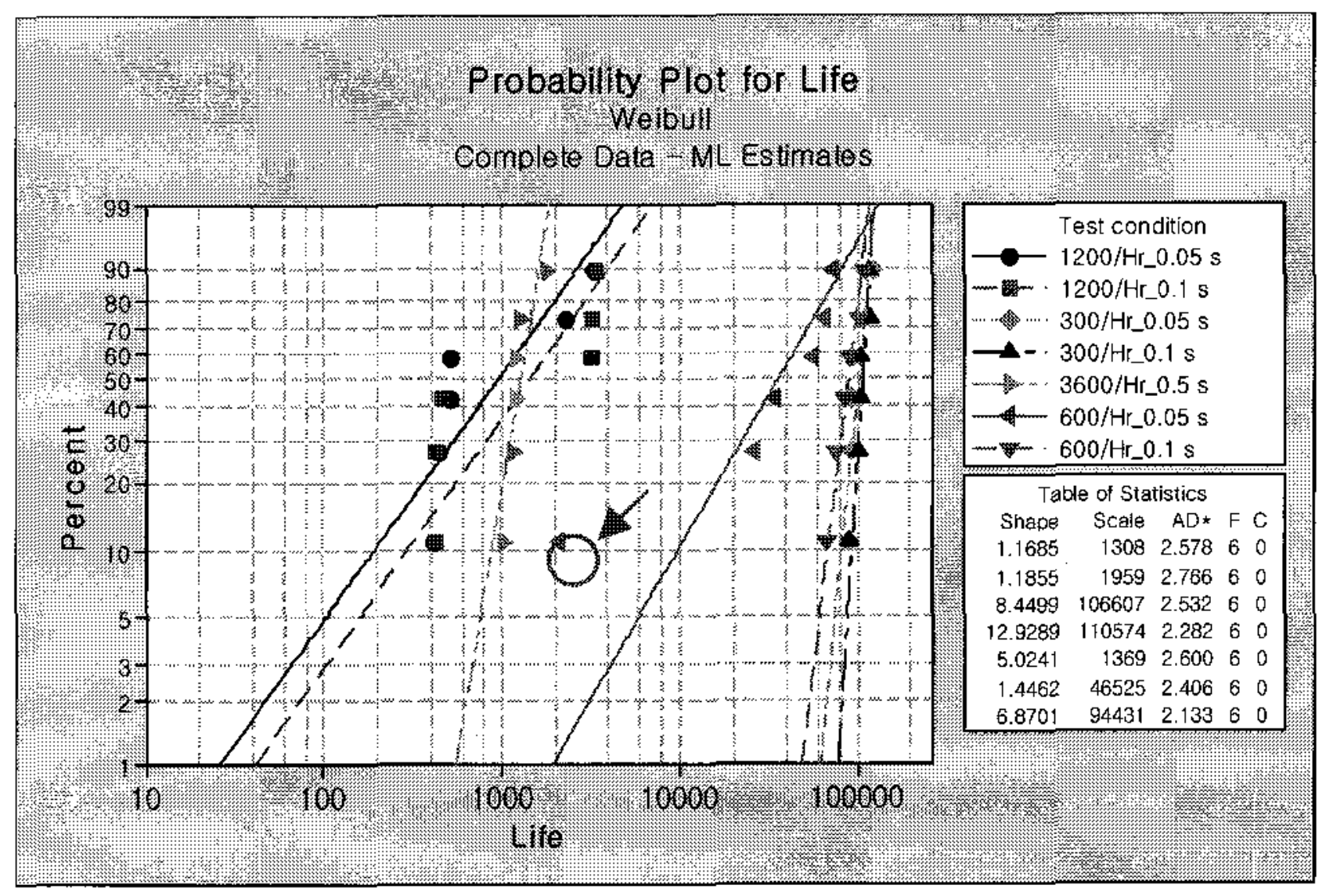

Fig. 12. The probability plot of raw data 


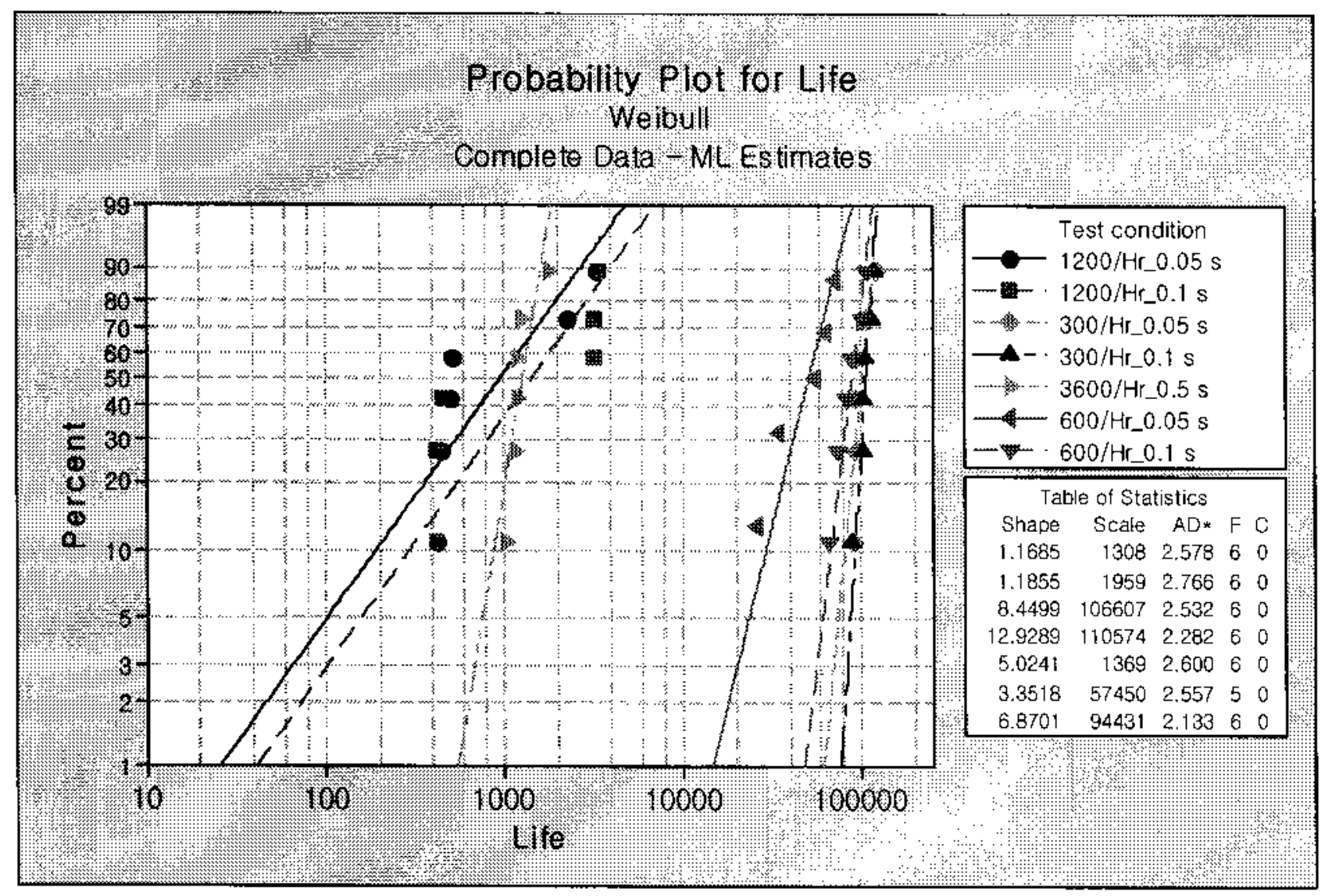

Fig. 13. The probability plot of outlier removed

Two sample T-tests are conducted, the equality of both $0.05 \mathrm{~s}$ and $0.1 \mathrm{~s}$ is possible to be accepted because the PValue is greater than 0.05 .

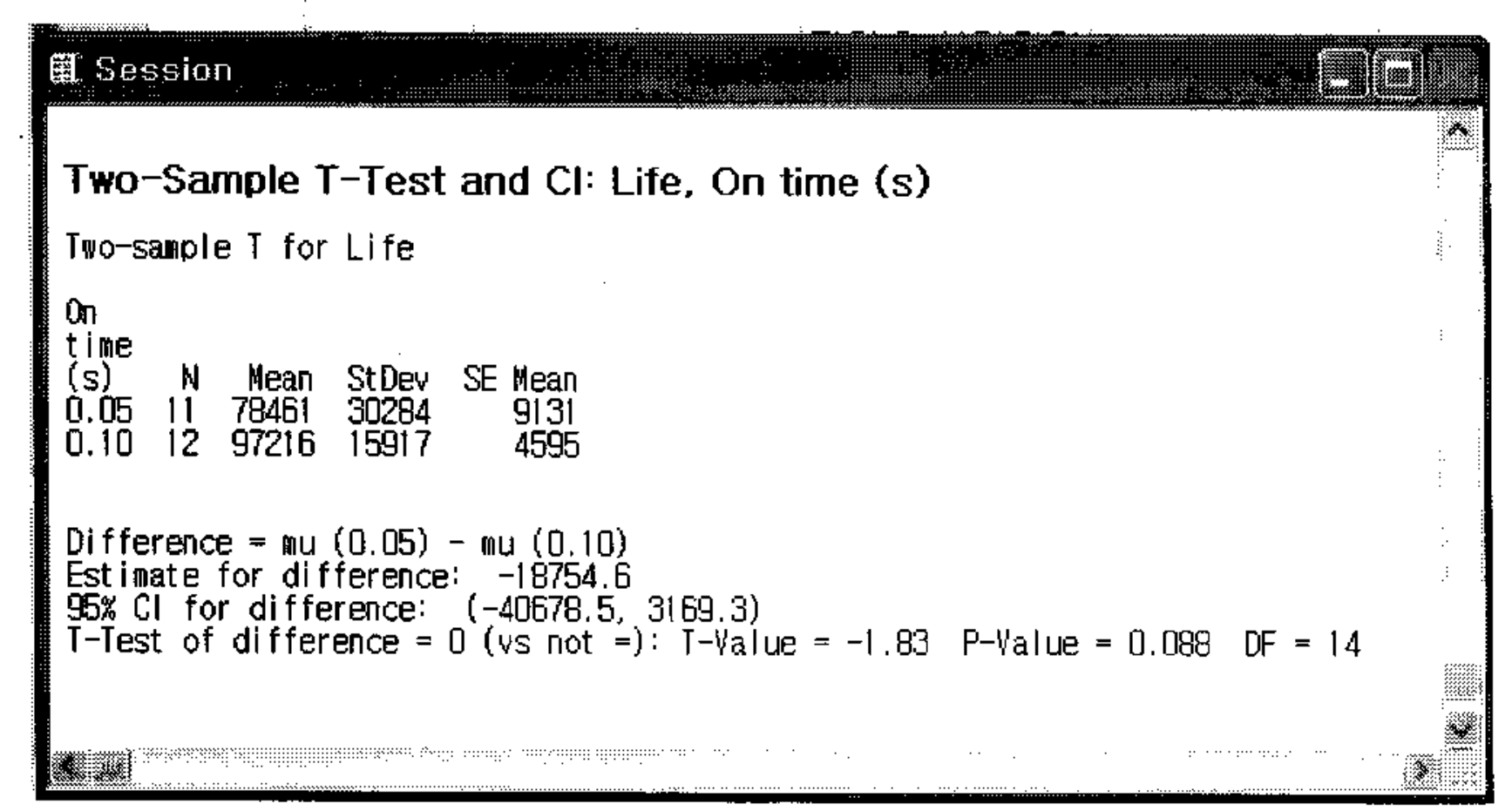

Fig. 14. The session window of two sample T-tests

Figure 15 indicates the probability plot of both $300 / \mathrm{Hr}$ and $600 / \mathrm{Hr}$.

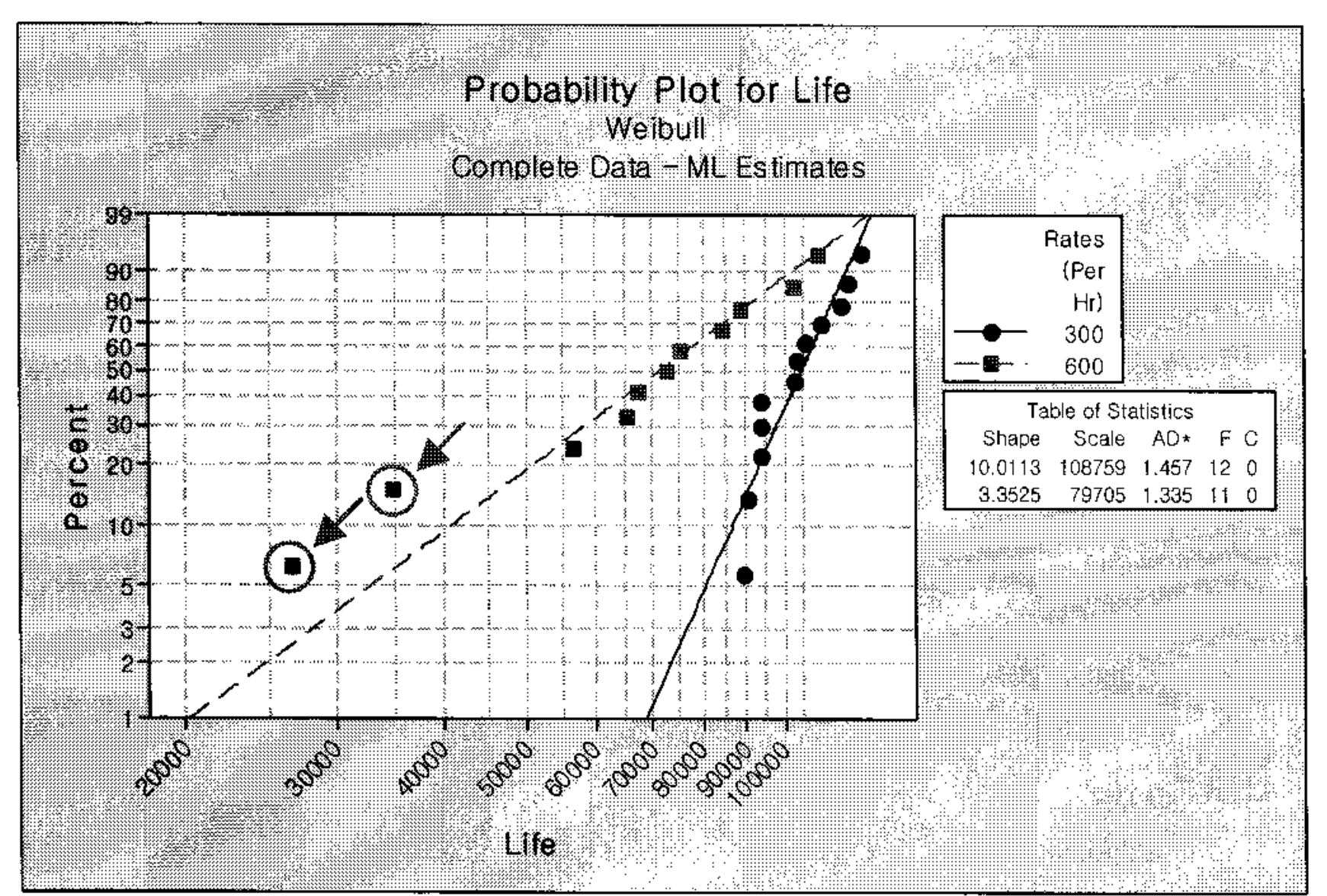

Fig. 15. The probability plot of both $300 / \mathrm{Hr}$ and $600 / \mathrm{Hr}$

Two points are considered to be outliers because of the long distance from other life data. In this study, I want to analyze the life data with the exception of two points in order to determine the acceleration factor.

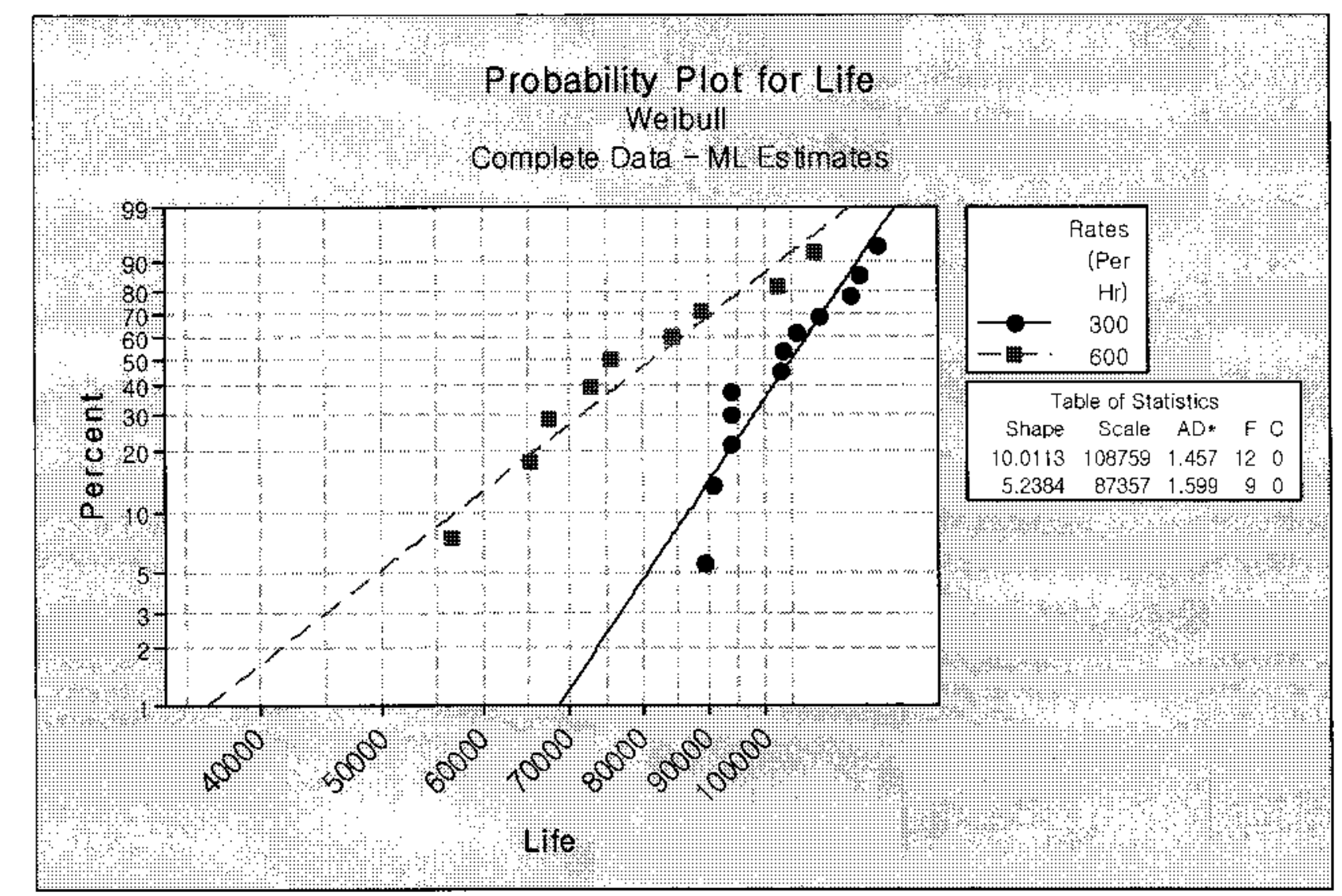

Fig. 16. The probability plot of both $300 / \mathrm{Hr}$ and $600 / \mathrm{Hr}$ without the outliers

The tests for equal shape and scale parameters are shown in Fig. 17. As a result of this, the acceleration is verified.

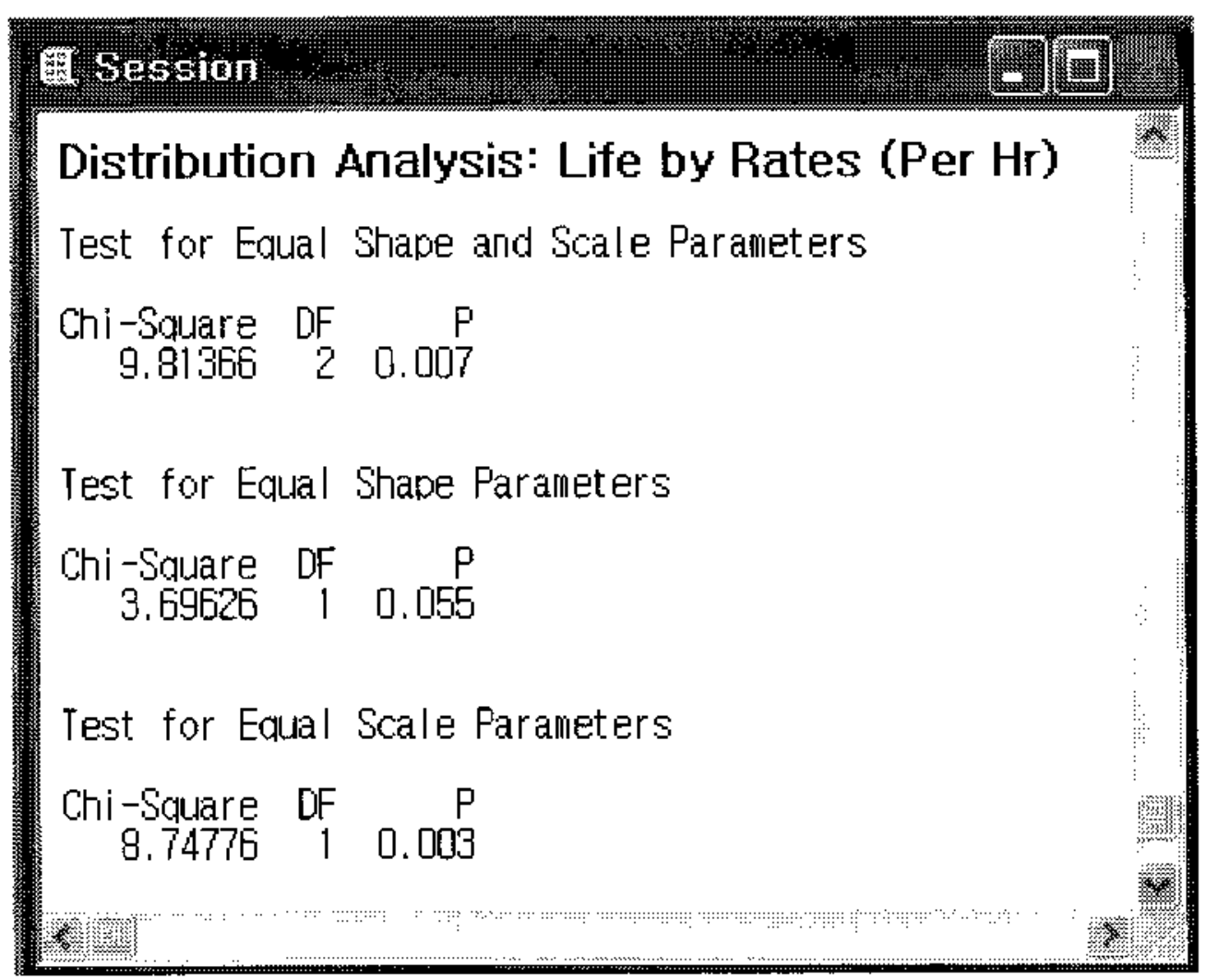

Fig. 17. The session window of the test for equal shape and scale parameters

Because the P-Value of the test for equal shape parameters is greater than 0.05 and the P-Value of the test for equal scale parameters is lower than 0.05 , the acceleration is accepted.

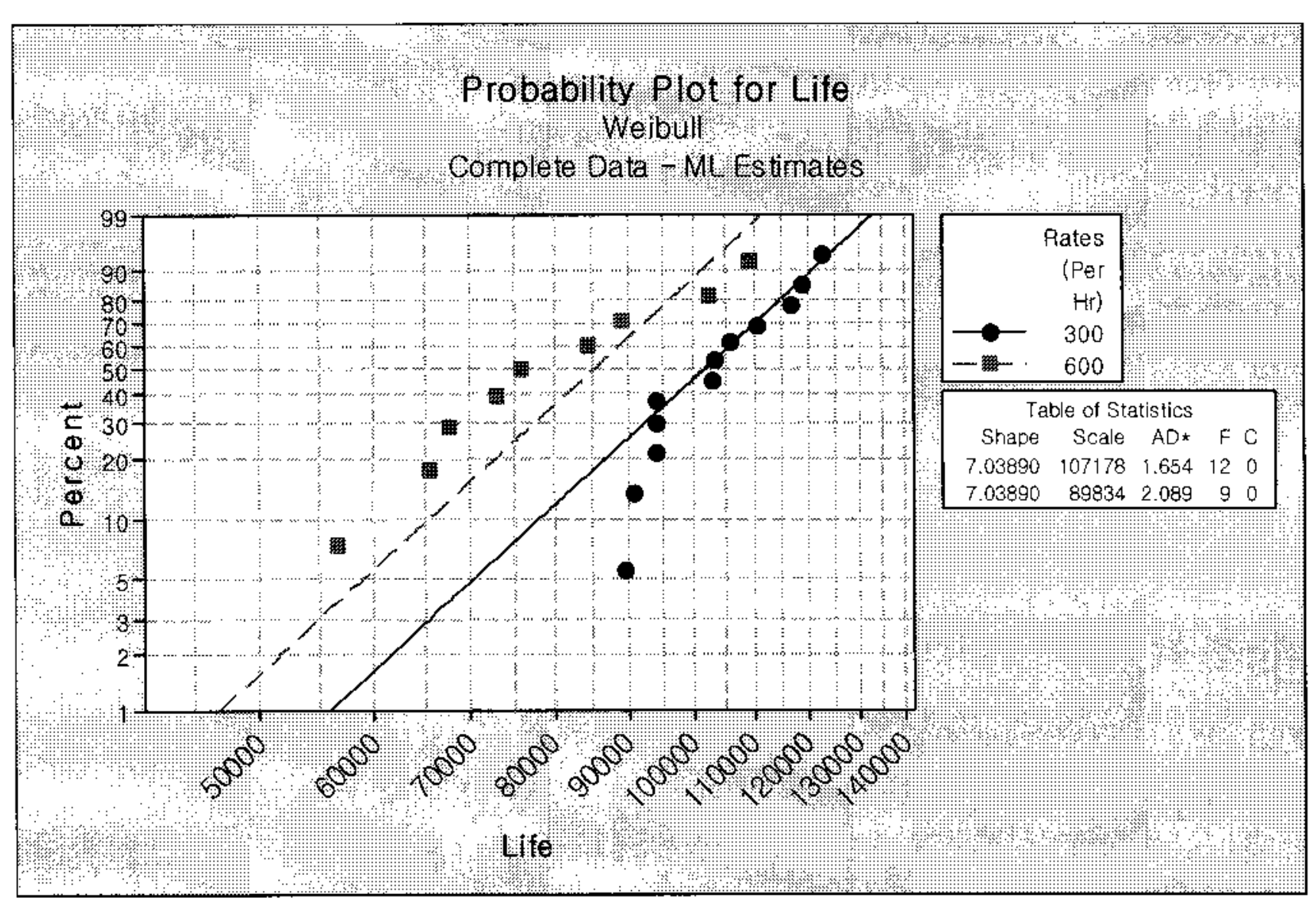

Fig. 18. The probability plot of common shape parameter 
In order to determine the acceleration factor, the parametric distribution analysis is performed on the assumed common shape parameter.

Figure 18 indicates the result of probability plot for life. The acceleration factor is approximately 1.2 .

\section{Conclusion}

The electrical current is applied to the ALT of the magnetic contactor and the number of operating cycles is used for acceleration level. The test conditions are determined by using the optical temperature sensor which measures the nearest area of the arc. Moreover, this study shows the method of choosing the acceleration level. In this paper the acceleration limit is shown in $600 / \mathrm{Hr}$ but further study will be conducted for both $800 / \mathrm{Hr}$ and $1000 / \mathrm{Hr}$. When they are conducted, perhaps the acceleration factor will be increased. The next topic for investigation will be to find the correlation among IEC60947-4-1, UL508, and the manufacturer standard regarding the electrical endurance test so that if just one test is conducted, other results are possible to be predicted. This will save the testing time and minimize the period of the product development.

\section{Acknowledgements}

The authors would like to acknowledge the Power Testing \& Technology Institute (PT\&T, LS industrial systems), Cheongju, Korea, for conducting the tests and for failure investigations.

\section{References}

[1] Wayne Nelson, "Accelerated Testing-Statistical Models, Test Plans, and Data Analyses, Ed. New York: John Wiley \& Sons, 1990, pp. 63-64.

[2] Anderson, Sweeney, Williams, "Modern Business Statistics", Ed, Ohio: South-Western, 2003.

[3] IEC International standard for Low-voltage switchgear and controlgear - (Standards style), IEC International Standard 60947-1, 2007.

[4] IEC International standard for Contactors and motor-starters-Electromechanical contactors and motor-starters (Standards style), IEC International Standard 60947-4-1, 2005.

[5] H. S. Ryu, G. H. Han, Y. I. Kwon, "A Study on Accelerated Life Test for Magnetic Switch Used in
Distribution System, in Proc. 33 th Summer Annu. Conf. KIEE, Korea, 2002, pp. 536-540.

[6] H. S. Ryu, S. Y. Park, G. H. Han, Y. I. Kwon, N. S. Yoon, "To Ensure A Product Reliability The Study on Accelerated Stress Tests for Magnetic Switch Used In Power Distribution System, in Proc. 36 th Summer Annu. Conf. KIEE, Korea, 2005, pp. 377-380.

[7] LabVIEW Manual, National Instrument Corporation, 2006.

[8] John Moubray, Reliability Centered Maintenance, 200 Madison Avenue, NY: INDUSTRIAL PRESS INC, 1997.

[9] H. S. Ryu, S. Y. Park, G. H. Han, Y. I. Kwon, N. S. Yoon, "Design and Analysis of an Accelerated Life Test for Magnetic Contactors", Journal of Electrical Engineering \& Technology, vol. 2, no. 2, pp. 188-193, Jun. 2007.

[10] H. S. Ryu, G. H. Han, N. S. Yoon, “Accelerated Life Test of Voltage and Temperature stresses for Magnetic Contactors in Power Distribution", International Conference on Electrical Engineering, pp. ICEE-026, July 2007.

[11] H. S. Ryu, G. H. Han, N. S. Yoon "Degradation Test through measuring vibration for Magnetic Contactors in Power Distribution", International Conference on Electrical Engineering, pp. ICEE-027, July 2007.

[12] Digital Optical Fiber Point Sensor for HighTemperature Measurement, Journal of Lightwave Technology, Vol. 13. No. 7, July 1995.

[13] Monitoring of Power Transformer winding Temperature Using Robust Fiber Optic Sensing System, Luxtron.

[14] Paul G. Slade, "Electrical Contacts, 270 Madison Avenue, New York: Marcel Dekker Inc, 1999, pp. 792-795.

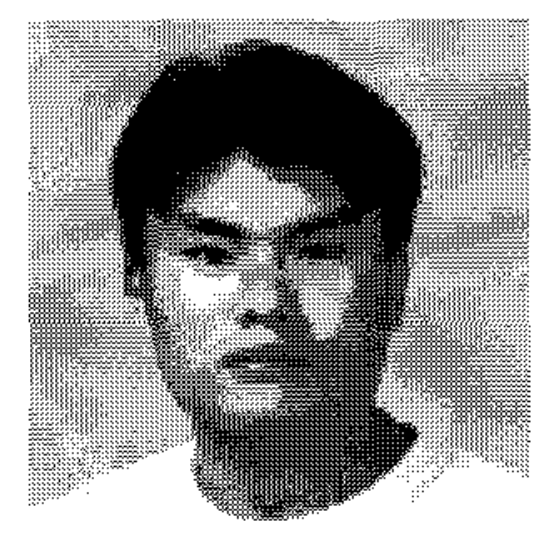

\section{Haeng-Soo Ryu}

He received his B.S and M.S degrees in Electrical Engineering with a focus on power system stability and renewable energy source from the University of Dongguk, Seoul Korea, in 1999 and 2001, respectively. He is currently working toward his Ph.D. degree in Electrical Engineering with a focus on the Physics of failure and Reliability testing at the National University of Chungbuk, Korea. 


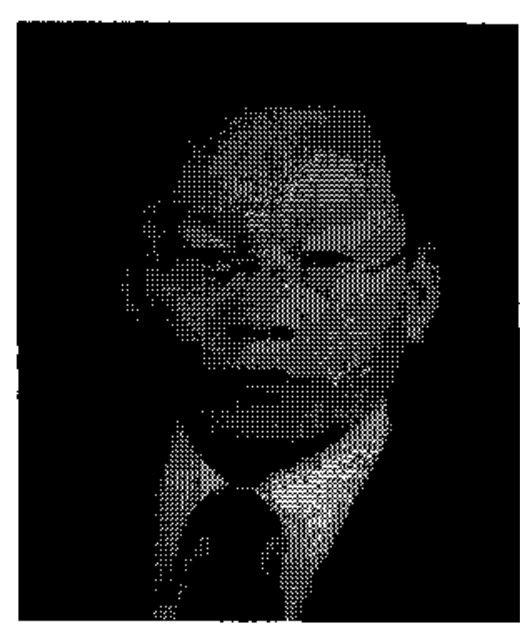

\section{Gyuh-Han Han}

$\mathrm{He}$ received his B.S. degree in Electrical Engineering from Chungbuk National University and his M.S. degree in Industrial Engineering with a focus on reliability prediction and accelerated life testing from the Cheongju University of Korea in 1985 and 2006 respectively. His interests are in the physics of failure and reliability testing.

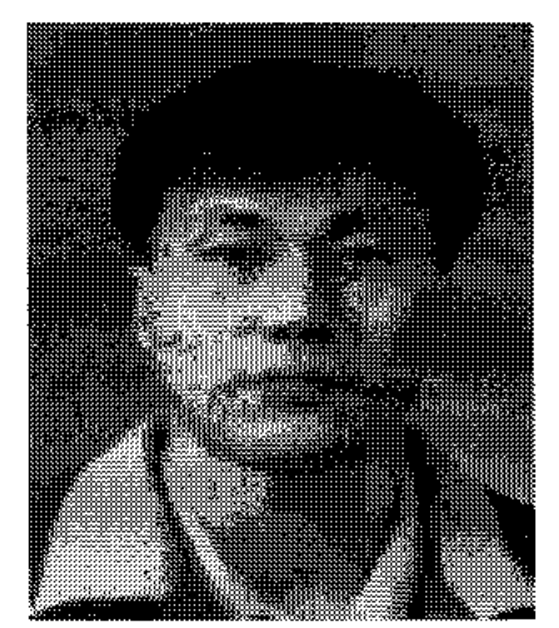

Nam-Sik Yoon

He received his B.S. degree from Sogang University and his M.S. and $\mathrm{Ph} . \mathrm{D}$. degrees in Physics from the Korea Advanced Institute of Science and Technology in 1989, 1992, and 1996 respectively. Since 1999 , he has been with the Chungbuk National University of Korea, as a Professor in the School of Electrical and Electronic Engineering. His research interests are in modeling and development of new plasma devices, and also, the physics of failure and reliability testing of electrical devices. 